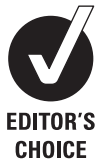

- Additional appendices are published online only. To view the files please visit the journal online (http://bjsm.bmj.com/ content/46/9.toc).

${ }^{1}$ Melbourne School of Physiotherapy, The University of Melbourne, Melbourne, Australia

2Melbourne School of Engineering, The University of Melbourne, Melbourne Australia

${ }^{3}$ Melbourne Brain Centre, Florey Neurosciences Institute, University of Melbourne,

Australia

${ }^{4}$ International Centre for Allied Health Evidence (iCAHE), University of South Australia, Adelaide, Australia

${ }^{5}$ School of Health and Rehabilitation Sciences, University of Queensland, Brisbane, Australia

\section{Correspondence to}

Kay Crossley, Division of Physiotherapy, School of Health and Rehabilitation Sciences, University of Queensland, Brisbane, Australia 4072;

k.crossley@uq.edu.au

Received 21 July 2011 Accepted 3 November 2011 Published Online First 22 December 2011

\title{
Hip arthroscopy for intra-articular pathology: a systematic review of outcomes with and without femoral osteoplasty
}

\author{
Joanne L Kemp ${ }^{1,2}$ Natalie J Collins, ${ }^{1,2}$ Michael Makdissi, ${ }^{1,3}$ Anthony G Schache, ${ }^{2}$ \\ Zuzana Machotka, ${ }^{4}$ Kay Crossley $1,2,5$
}

\begin{abstract}
Background Arthroscopy is increasingly used to improve pain and function in athletes with hip joint pathology. Surgical techniques have evolved to utilise arthroscopic femoral osteoplasty to address potential morphological contributors to pathology.

Purpose Investigate pain and function outcomes following hip arthroscopy with and without femoral osteoplasty in individuals with intra-articular hip pathology. Study design Systematic review.

Methods A comprehensive search strategy identified studies that evaluated the outcome over at least 3 months following arthroscopy for intra-articular hip pathology, using patient-reported outcomes of pain and/or function. Methodological quality was evaluated (Downs and Black scale), and effect sizes calculated when sufficient data were available.
\end{abstract}

Results Twenty-nine studies of moderate methodological quality were included. Of 16 studies investigating arthroscopy alone, two studies showed large effects (3.12-5.46) at 1-2 years. Pain reduction and functional improvement (median 47\%) were consistently reported by the remaining 14 studies up to 10 years postsurgery. Of 15 studies investigating arthroscopy with osteoplasty, nine papers showed mostly large effects (0.78-2.93) over 6-28 months. Adverse events were minimal (7\% of participants, 12 studies, predominantly transient neuropraxia (83\%)).

Conclusion Current evidence indicates that hip arthroscopy can significantly reduce pain and improve function in patients with intra-articular hip pathology. While benefits of arthroscopy alone can persist up to 10 years postsurgery, effects of osteoplasty beyond 3 years need to be established. Future studies should investigate rehabilitation in this population, and the impact of surgery on development of osteoarthritis.

\section{INTRODUCTION}

Intra-articular hip pathology is a common cause of hip and/or groin pain, ${ }^{12}$ and may be associated with considerable morbidity in young active populations. ${ }^{34}$ In recent years, arthroscopic surgery has contributed to advancements in assessment and management of hip pathology; however, the complex anatomical nature and multifactorial sources of pain within the hip and groin regions continue to make diagnosis and management of such injuries a challenge to clinicians. ${ }^{5}$ Hip labral tears have been identified at arthroscopy in patients with moderate to severe groin pain, ${ }^{3}$ and professional National Hockey League (NHL) players with long-standing hip and groin pain. ${ }^{4}$ Ligamentum teres pathology has also been observed during arthroscopy in athletes presenting with hip and groin pain. ${ }^{6}$ The total number of hip arthroscopies performed internationally is growing rapidly, with more than 30000 procedures performed in 2008 , and an expected annual increase of $15 \%$. Moreover, surgical techniques have advanced significantly in recent years. Initial procedures typically involved debridement (eg, of the labrum and/or cartilage). With improvement in surgical techniques and advancement in understanding of hip pathology, the recent focus has been on addressing abnormal bony morphology (ie, camor pincer-type femoro-acetabular impingement (FAI)). Studies to date have demonstrated that FAI and acetabular dysplasia are strongly associated with the increased severity of labral pathology ${ }^{8}$ and may play a significant role in the development of early hip osteoarthritis. ${ }^{9-11}$ Current techniques have expanded to include osteoplasty of the femoral neck and/or acetabulum as well as the debridement/repair of the acetabular labrum in an effort to address intra-articular hip pathology and the long-term implications of abnormal bony morphology (ie, cam- or pincer-type FAI).

There is an increasing body of literature examining the outcomes of pain and physical function after hip arthroscopy. ${ }^{12-16}$ Data from studies involving arthroscopic labral debridement demonstrate good short- to medium-term results. Two systematic reviews evaluated the outcomes of hip arthroscopy for labral pathology, reporting $65-85 \%$ patient satisfaction up to 40 months postsurgery. ${ }^{13} 15$ However, patient satisfaction was reduced in the presence of significant chondropathy. ${ }^{15}$ Four systematic reviews have evaluated outcomes following hip arthroscopy for FAI, with all concluding that short-term outcomes (up to 2.5 years) are positive. ${ }^{12-14} 16$ Pain reduction, improved physical function or increased patient satisfaction were reported for all included studies in the reviews by Baldwin et a ${ }^{14}$ (six studies) and $\mathrm{Ng}$ et a ${ }^{12}$ (23 studies). The remaining two systematic reviews reported similar percentages of FAI patients who achieved good or excellent outcomes $(67-93 \%)^{13}$ and improvements in pain and function (68-96\%). ${ }^{16}$ Once again, poor outcomes were observed in the presence of co-existing chondropathy. ${ }^{12} 13$ Thus, while it appears that there are shortterm positive outcomes following hip arthroscopy for FAI, longer-term results remain unclear. 
While the published systematic reviews have increased understanding of outcomes after hip arthroscopy, they are associated with notable limitations. Importantly, all reviews were limited by the lack of randomised clinical trials (RCTs) available for inclusion; none used validated critical appraisal tools to analyse the quality of included studies, and effect sizes for outcomes were calculated in one study only. ${ }^{12}$ Since the most recent of these reviews, there have been a further 21 studies published investigating hip arthroscopy outcomes, and findings of these may alter previous conclusions. Furthermore, the published systematic reviews consider pathologies such as labral tears and FAI to be separate entities. Since contemporary practice indicates that hip pathologies often co-exist, it is inappropriate to restrict eligibility criteria according to individual hip pathologies. Appraisal of studies on the basis of surgery (ie, arthroscopy alone, or combined with osteoplasty) may be a more appropriate and clinically meaningful approach.

The objective of this study was to conduct a systematic review examining the outcomes of pain and physical function following hip arthroscopy for intra-articular hip joint pathologies.

\section{MATERIALS AND METHODS}

The systematic review protocol was developed according to guidelines outlined in the PRISMA Statement. ${ }^{17}$ Literature search criteria and methods were proposed and agreed upon by three authors (JK, NC and KC), and were established a priori to minimise selection bias.

\section{Eligibility criteria}

Studies were included that utilised participants aged 17 years or over who were scheduled for or had undergone hip arthroscopy surgery as a primary intervention for intra-articular hip pathology. Studies that followed participants over at least 3 months, and utilised a patient-reported measure of pain and/or function, were included. All quantitative study designs were considered, including RCTs and other prospective or retrospective study designs (minimum level IV evidence). ${ }^{18} 19$ Studies were excluded if (1) they performed open surgeries; (2) they addressed infection, osteoarthritis or synovial chondramatosis as primary pathology; (3) they were case series with less than five participants or (4) they were published in a language other than English or in a non-peer-reviewed journal. This systematic review included all non-osteoarthritic pathologies. Papers where osteoarthritis was the primary pathology were excluded, due to significant differences in outcomes observed in previous systematic reviews between participants with and without osteoarthritis. ${ }^{12} 16$ As such, we felt that the outcomes for hip arthroscopy in which osteoarthritis was the primary pathology warranted a separate review outside the scope of this study.

\section{Search strategy}

A comprehensive, reproducible search strategy was performed on the following databases between January 1990 and May 2010: Scopus, Medline, CINAHL, Pubmed, Ausport, SportsDiscus, PEDro, the Cochrane Library, PsychINFO and Google scholar. January 1990 was selected for retrieval of the earliest record due to the paucity of literature prior to this date, and vast changes in this procedure over the past two decades (Appendix 1 see online for search strategy). Reference lists of suitable studies were manually searched for relevant papers.

Titles and abstracts were screened for potentially relevant studies by two independent reviewers (AS and MM). Any disagreements regarding inclusion were resolved by an independent arbitrator (KC). Full text versions of identified studies were retrieved for final eligibility screening.

\section{Quality evaluation}

The Downs and Black checklist ${ }^{20}$ was used to appraise the methodological quality of included studies (see online Appendix 2 for checklist) since it has adequate reliability and validity for assessing RCTs and non-randomised studies. ${ }^{20-22}$ Included studies were rated by two independent reviewers (JK and NC), who were blinded to author, affiliations and publishing journal. Any disagreements between reviewers were

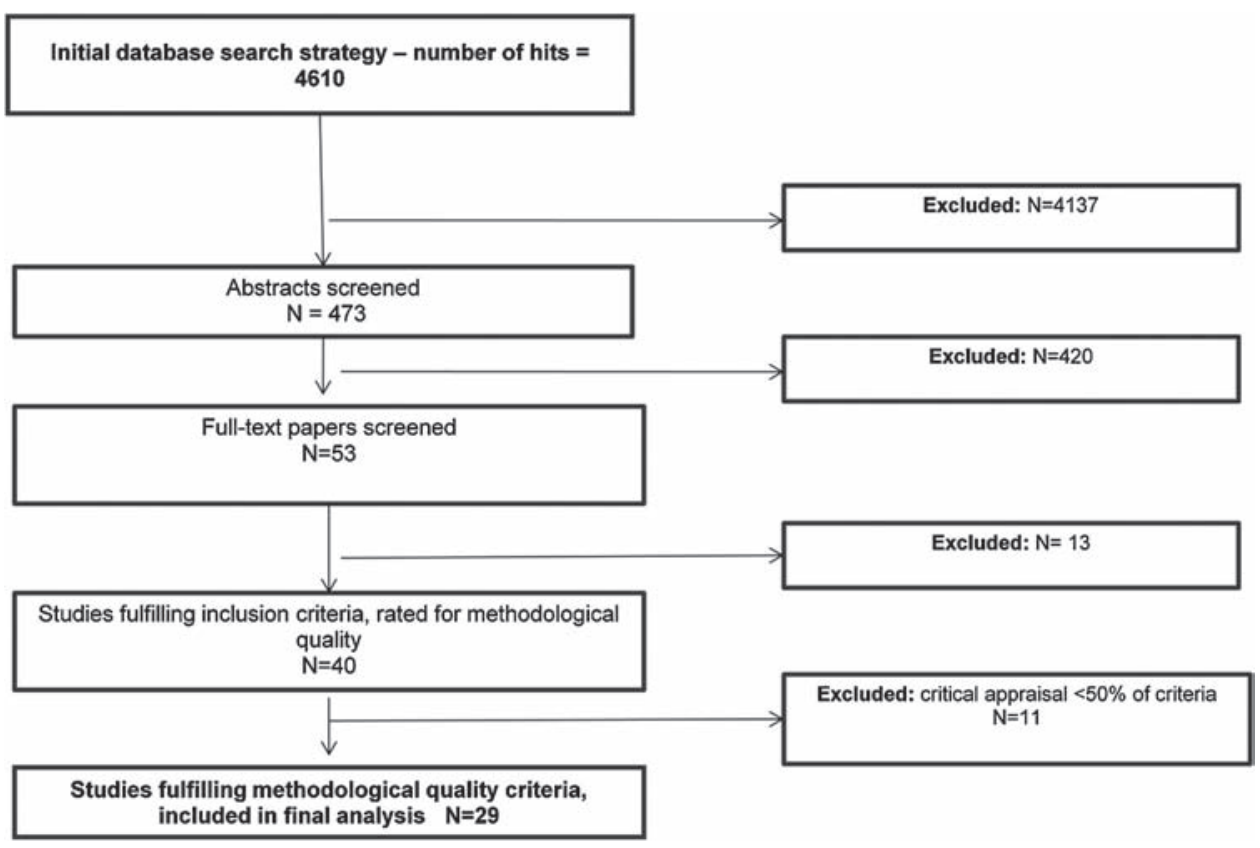

Figure 1 Flow chart of search results. 
Table 1 Summary of outcome measures used in 29 studies evaluating the outcomes of hip arthroscopy surgery

\begin{tabular}{|c|c|c|c|c|c|c|}
\hline $\begin{array}{l}\text { Outcome } \\
\text { measured }\end{array}$ & $\begin{array}{l}\text { Outcome } \\
\text { measure used }\end{array}$ & $\begin{array}{l}\text { Number } \\
\text { of studies }\end{array}$ & Studies using measure & $\begin{array}{l}\text { Reliability, validity and } \\
\text { responsiveness (non-hip } \\
\text { arthroscopy conditions) }\end{array}$ & $\begin{array}{l}\text { Reliability, validity and } \\
\text { responsiveness in hip } \\
\text { arthroscopy }\end{array}$ & Reference \\
\hline \multicolumn{7}{|l|}{ Pain } \\
\hline & & & & Valid & & \\
\hline \multicolumn{7}{|c|}{ Pain and function } \\
\hline & MHHS & 21 & $43033-364045-56$ & Valid & Valid & 42 \\
\hline & NAHS & 7 & $333437-394147$ & Reliable & Reliable & 42 \\
\hline & & & & Valid & Valid & \\
\hline & HOS & 1 & 47 & Reliable & Reliable & 4279 \\
\hline & & & & Valid & Valid & \\
\hline & & & & Responsive & Responsive & \\
\hline & PMA & 1 & 59 & Reliable & NR & 82 \\
\hline & & & & Valid & & \\
\hline & $\mathrm{DO}$ & 1 & 36 & NR & NR & 36 \\
\hline & SF-12 & 1 & 45 & Reliable & NR & 83 \\
\hline & & & & Valid & & \\
\hline
\end{tabular}

Function

$$
\text { SFS }
$$

1

38

NR

NR

84

DO, dance questionnaire; HHS, Harris hip score; HOS, hip outcome score; MHHS, modified Harris hip score; NAHS, non-arthritic hip score; NR, not reported: PMA, Postel Merle d'Aubigne score; SF-12, short form 12; SF-36, short form 36; SFS, sports frequency score; VAS visual analogue scale; WOMAC, Western Ontario and McMaster universities osteoarthritis index.

discussed in a consensus meeting and an independent arbitrator (KC) employed when consensus could not be met. To maintain a benchmark of moderate to high-study quality, it was agreed a priori that studies that scored a total score of greater than 13 points were included in the final evaluation.

\section{Data management and statistical analysis}

Inter-rater agreement on the Downs and Black criteria was evaluated using the $\kappa$ statistic. $^{23}$

Data were extracted by one reviewer (JK). Population characteristics (age, gender, pathology, duration of symptoms), outcome measures utilised, length of follow-up and details of surgical interventions were collated. In order to allow consideration of surgical outcomes in the context of treatment risks, information regarding adverse events was also obtained.

Mean and SD for each outcome measure were extracted for calculation of effect sizes. Where sufficient data were not presented, corresponding authors were contacted to request additional data. Effect sizes were calculated as the difference between the preoperative and follow-up means, divided by the within-group preoperative SD. ${ }^{24}$ Effect size magnitude was interpreted as: $\geq 0.8$ large effect; $0.5-0.8$ moderate effect and $0.2-0.5$ weak effect ${ }^{24-26} ; 95 \%$ CI for effect sizes were estimated by dividing the lower or upper CI for the mean difference by the population SD. ${ }^{27}$

\section{RESULTS}

\section{Search strategy}

The comprehensive search strategy identified 473 papers for evaluation beyond title level, and 53 papers for full-text evaluation (figure 1). On further evaluation of full texts (JK, ZM and NC), 13 papers were excluded, including two studies where the primary pathology of participants was osteoarthritis. ${ }^{28} 29$ Forty studies fulfilled all inclusion criteria and underwent critical appraisal.

\section{Methodological quality}

The initial overall agreement between the two independent raters was very high $(\kappa=0.820)$, concurring on 990 of a possible 1080 items. Consensus was reached on all items following initial discussion. Inter-rater reliability for individual items ranged from $\kappa=0.404$ (moderate agreement) to $\kappa=1.0$ (perfect agreement).

Methodological quality scores of the 40 included studies varied widely, from 9 to 21 of 31 points (mean 15 (SD 3)) (see online Appendix 3). Eleven papers received a quality score of less than or equal to 13 and were subsequently excluded from further analysis, leaving 29 papers for final inclusion. Two papers were included in non-osteoplasty and osteoplasty groups. ${ }^{30} 31$

\section{Participants}

Participant characteristics varied between the 29 included studies (tables 1 and 2). Sample sizes ranged from $10^{32}$ to $166^{33}$ participants. One study included only female participants, ${ }^{32}$ while two studies utilised athletic populations of male-only elite sports (United States (NHL), Australian Rules Football). ${ }^{4} 34$ The remaining 26 studies had representation from both genders, with the percentage of women ranging from $25 \%{ }^{33}$ to $61 \%$. ${ }^{35}$ The mean age of individual cohorts ranged from 20 years $^{36}$ to 47 years, ${ }^{37}$ while the overall mean age across all studies was $35^{4}$ years. While most studies included participants based on pathology, three studies utilised the activity type as an inclusion 


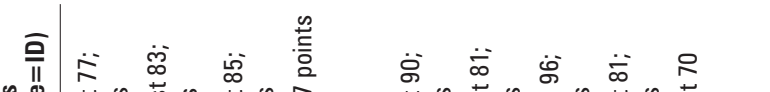

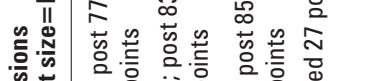

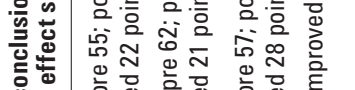

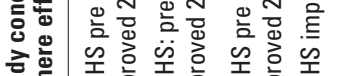

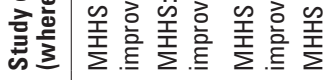

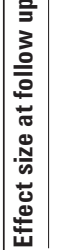

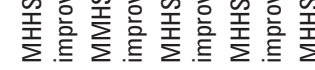

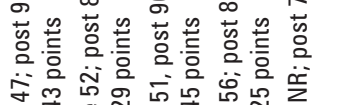

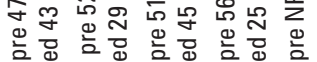

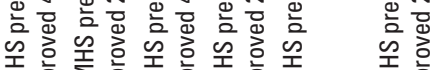

空 을 $\ddot{-}$

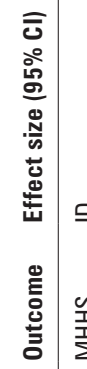

宁

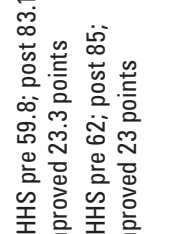

$\stackrel{2}{2}$

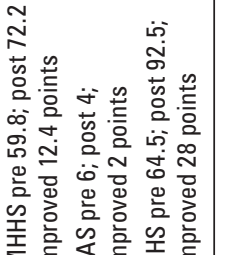

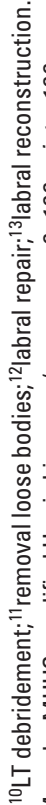

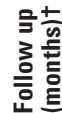

至言

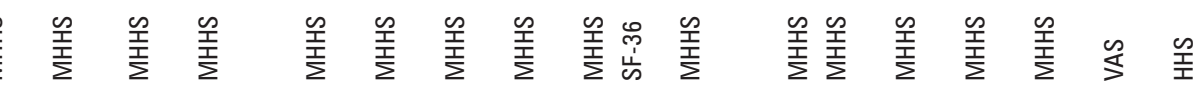
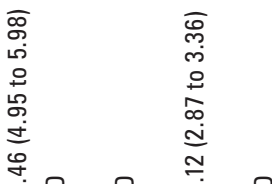

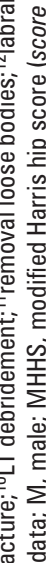

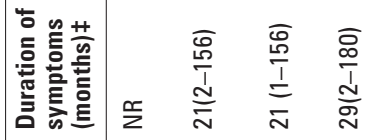

$\frac{t}{\frac{\pi}{m}}$

㡺兽品

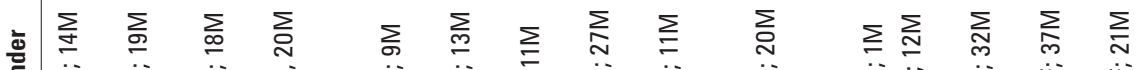

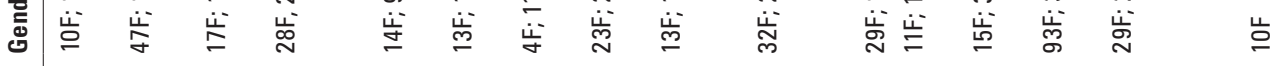

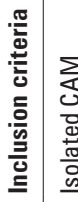

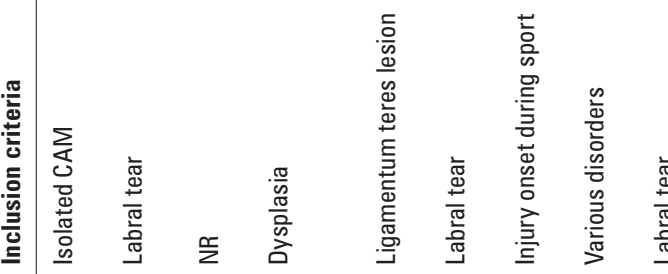

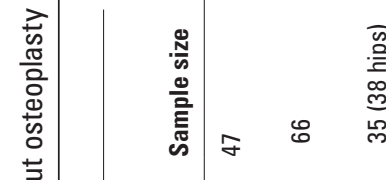

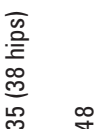

ก $\stackrel{\sim}{\circ}$

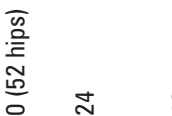

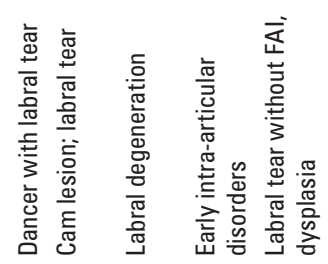

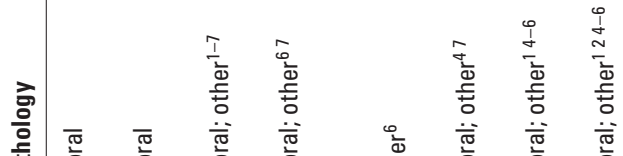

贾

离

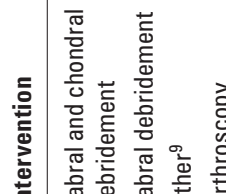

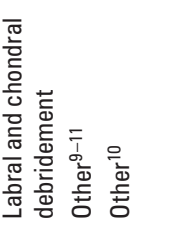

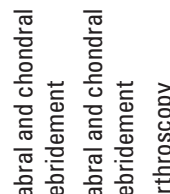

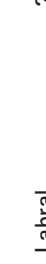

ㅇำ

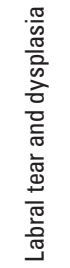

窇.

这. 点

竞市

읗 홍

흥 홍

is

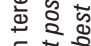

害要

产.

is 8

का

은 응ㅇ

든옹

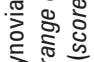

कि

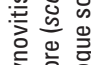

究

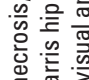

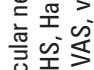

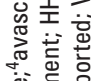

空

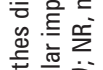

言

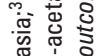

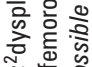


criteria ${ }^{4} 3436$ The mean symptom duration prior to surgery was reported in 11 studies, ranging from 6 to 36 months, with the mean duration being $24^{8}$ months.

\section{Outcome scores}

The included studies utilised 11 patient-reported outcomes (PROs) of pain and function (table 1). The Non-arthritic Hip Score (NAHS) was reported by seven studies 33 34 37-41 and has been shown to be reliable and valid in a hip arthroscopy cohort. ${ }^{42} 43$ The Harris Hip Score (HHS) includes an observer measure of the hip range of motion in addition to the PROs and was used in two studies. ${ }^{32} 44$ The most frequently used measure was the modified Harris Hip Score (MHHS) (21 studies), ${ }^{4}$ 30 33-35 40 45-56 which was adapted from the HHS (physical range of motion measures removed). While the MHHS has construct validity for hip arthroscopy, ${ }^{42}$ its reliability has not been tested. The Hip Outcome Score (HOS) was utilised in only one study; ${ }^{47}$ however, this is the only outcome measure with demonstrated responsiveness in a hip arthroscopy population, ${ }^{42}$ which is the ability of the measure to detect a change (either improvement or worsening of pain and function) over time. ${ }^{57}$

\section{Findings}

The 29 included studies were grouped, based on the primary surgical procedure: hip arthroscopy without femoral osteoplasty, and hip arthroscopy with femoral osteoplasty. No studies used an RCT design. Most studies reported treating several pathologies concurrently at the time of arthroscopy. Follow-up times ranged from 4 months to 10 years. Seven studies reported sufficient data for effect size calculation 36404144495859 (tables 2 and 3 ). The authors of the remaining studies were contacted and six replied. ${ }^{33-35} 383945$ Wherever effect sizes were unable to be calculated, study conclusions were presented.

\section{Adverse events}

Adverse events were reported by 12 the 29 studies. Adverse events were reported in 52 of 700 participants (7\%) across the 12 studies. These included transient pudendal nerve hypoesthesia ( $n=22),{ }^{36} 3739414850$ transient lateral femoral cutaneous nerve hypoesthesia ( $n=14), 37394150525356$ transient sciatic nerve hypoesthesia $(n=6), 37394145$ heterotrophic bone formation ( $n=7),{ }^{44} 45$ myositis ossificans $(n=1),{ }^{56}$ tear of labia minora $^{37}(n=1)$ and complex regional pain syndrome $(n=1){ }^{3}$

\section{Hip arthroscopy without femoral osteoplasty}

Sixteen papers investigated the outcomes of hip arthroscopy without femoral osteoplasty $3032353645-48$ 50-56 (table 2). Only three papers utilised a prospective design 314748 and the remaining papers retrospective. The majority of studies were case series, with only two comparative studies. ${ }^{30} 31$ The mean quality score for the 16 studies was 16 , with the highest score of 20 only obtained by one study. ${ }^{47}$

A range of intra-articular hip pathologies were investigated, including labral pathology, 334748 isolated ligamentum teres pathology ${ }^{53}$ and labral pathology co-existing with other pathology (table 2). Despite the variation in pathologies recorded, postoperative improvements in pain and function were consistently reported. Furthermore, improvements were maintained over longer follow-up periods, with improvements seen up to 10 years.

Of the 16 studies, the effect sizes could only be calculated for two. ${ }^{3536}$ Significant large effects on the MHHS were found for both studies 1-2 years after surgery (figure 2). However, the characteristics of included participants differed between the two studies. Kocher et $a^{\beta 6}$ examined the effect of labral debridement in 30 ballet dancers (mean age 20 years) with labral pathology as their primary diagnosis, while Prather et $a^{35}$ performed arthroscopy on 130 individuals (mean age 31 years) in whom labral pathology co-existed with unspecified FAI and chondropathy. Kocher et al ${ }^{\beta 6}$ also reported poor

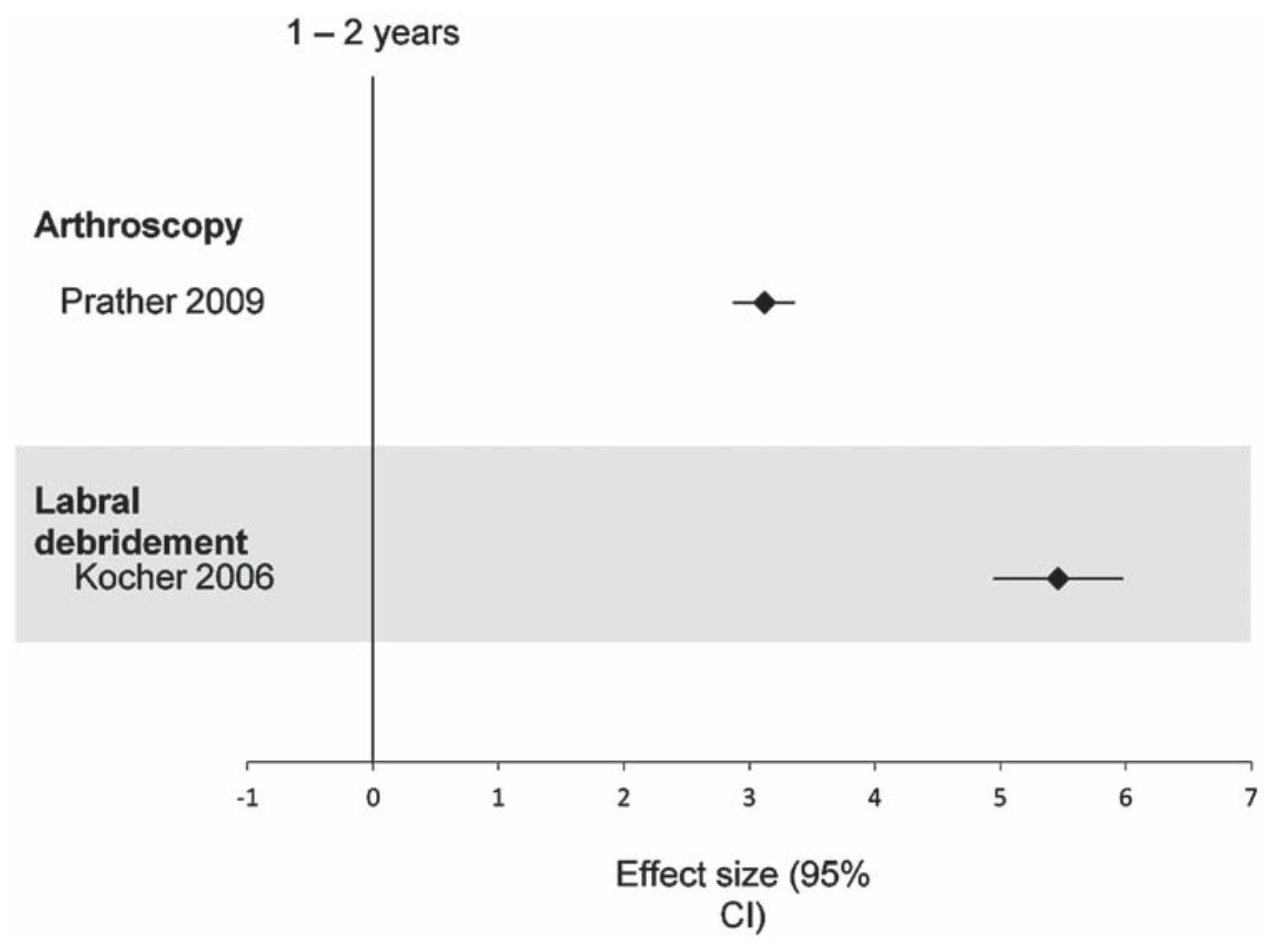

Figure 2 Effect sizes 1-2 years following arthroscopy without osteoplasty. Positive value favours intervention. Significant effect denoted by positive $\mathrm{Cl}(\mathrm{Cl})$. 


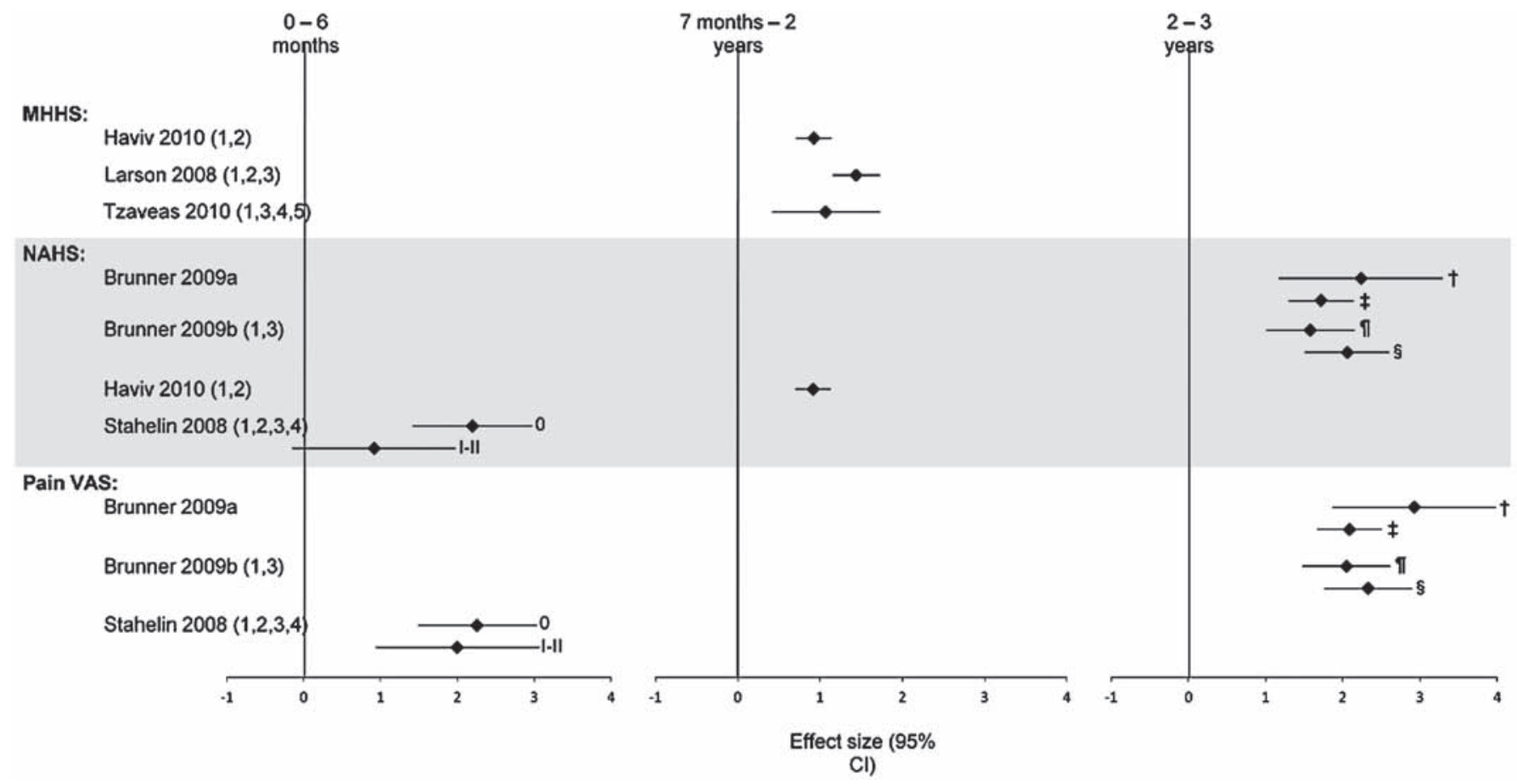

Figure 3 Effect sizes up to 3 years following arthroscopy with osteoplasty. Positive value favours intervention. Significant effect denoted by positive $\mathrm{Cl}$. Numbers in brackets indicate the intervention performed with femoral osteoplasty. 1: Labral debridement; 2: microfracture; 3 : chondral debridement; 4: labral debridement; 5: chondral repair. 0: Tonnis 0 classification; I-II: Tonnis I-II classification; † no sport participation; † sport participation; no CT navigation; § CT navigation.

outcomes of pain and function in those who had a co-existing chondral flap.

Of the remaining 14 studies, 12 used the MHHS as the primary PRO, $30474850-56$ while Yamamoto ${ }^{32}$ utilised the HHS. All but one study reported a statistically significant improvement of greater than 20 points (representing a percentage improvement of $34-88 \%)^{354}$ following surgery. Streich et al ${ }^{48}$ found an improvement of 12 points $(20 \%)$ on the MHHS, along with a decrease of 2 points of $10(33 \%)$ on a pain visual analogue scale (VAS). This suggests a postoperative improvement in pain alongside a smaller improvement in function.

One study retrospectively examined the effects of hip arthroscopy in 23 participants (mean age 28 years) with arthroscopically diagnosed isolated ligamentum teres pathology resulting from trauma. ${ }^{53}$ An improvement of 43 points (MHHS) was observed at a mean follow-up of 28 months and no differences in the outcome based on the type of trauma, the degree of rupture (full vs partial) or the presence of co-existing pathology.

All studies that reported the outcome separately for different hip pathologies found worse outcome to be associated with coexisting chondropathy at arthroscopy. ${ }^{515556}$ Byrd and Jones ${ }^{51}$ found the greatest mean difference in MHHS at 24 months $(29$ points) for participants without chondropathy, compared with those with chondropathy (16 points). A later study by Byrd and Jones ${ }^{56}$ reported that participants with no preoperative chondropathy demonstrated greater mean improvement on the MHHS at 10 years (39 points), compared with participants with preoperative chondropathy (five points).

\section{Hip arthroscopy with femoral osteoplasty}

Of 15 studies that examined the outcomes of hip arthroscopy with femoral osteoplasty (table 3), nine were prospective in design $^{4} 31$ 37-41 4958 and six were retrospective. ${ }^{30} 3334444559$
Only three studies utilised comparative designs ${ }^{30} 3139$ with the majority being case series. The methodological quality was similar to those that investigated arthroscopy only, with scores ranging from 16 to 21 (mean score 17). Importantly, the comparative studies did not adequately randomise individuals to either group, blind subjects or observers, and thus were susceptible to bias.

Nine papers presented sufficient data for effect size calculation across six outcome measures (figure 3). 3338394144454958 59 Significant large effects were mostly seen on all outcomes (MHHS, NAHS, VAS, WOMAC and PMA) up to 28 months following osteoplasty for cam-type and combined FAI, with additional labral and chondral debridement as appropriate. Six studies demonstrated positive postoperative outcomes, with five reporting an improvement of greater than 20 points on at least one measure. ${ }^{40313740}$ However, Singh et a ${ }^{34}$ found smaller improvements in their cohort of elite Australian Rules Football players (mean age 22 years), which may be attributed to higher preoperative scores and increased likelihood of ceiling effects. Two studies of participants with FAI differed from this trend. Although Stahelin et al ${ }^{11}$ reported a large significant effect on the NAHS in patients with FAI without co-existing osteoarthritis, the effect was largely diminished and not significant when osteoarthritis (Tonnis grade I or II) co-existed. Interestingly, the presence of osteoarthritis did not change the outcome on a pain VAS. Ilizaliturri et a ${ }^{58}$ demonstrated a significant moderate effect of surgery in those with FAI, although the modest effect size may be partly due to high preoperative scores.

The three comparative studies 303138 examined the outcomes of two arthroscopic techniques for isolated cam-type impingement. Bardakos and colleagues ${ }^{31}$ prospectively examined the effect of femoral osteoplasty compared with arthroscopy alone. A significantly higher proportion of participants 


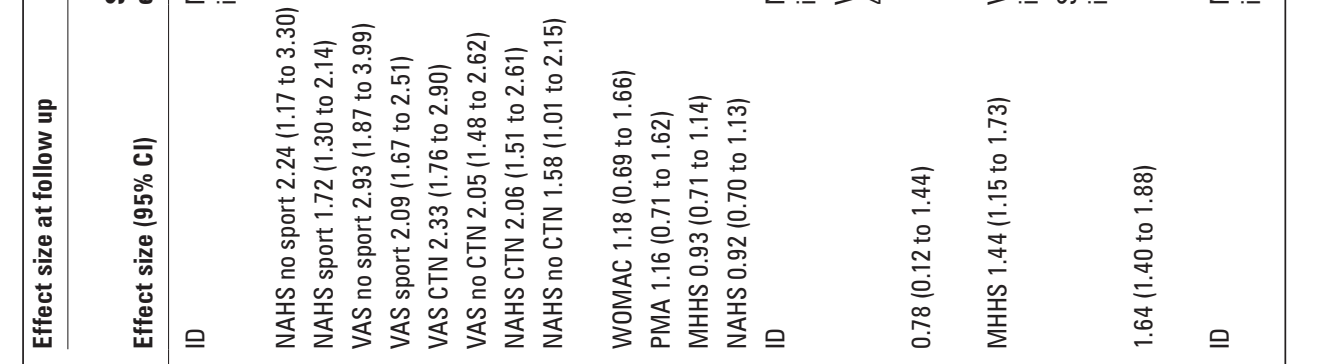

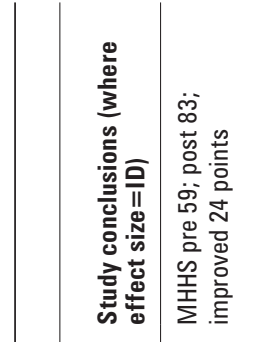

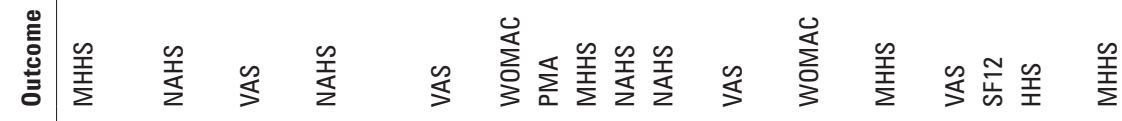

욱홍

言毫 $\simeq$

$\stackrel{\infty}{\sim}$

跣

言哭哭 采

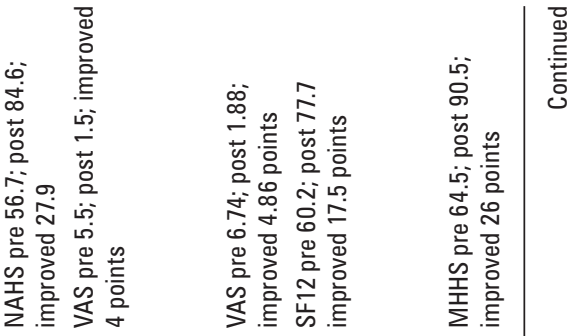

离

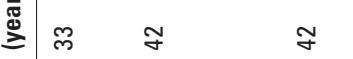

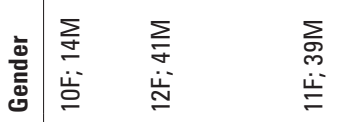

$\stackrel{2}{\infty}$

$\stackrel{4}{2}$

ก กิ

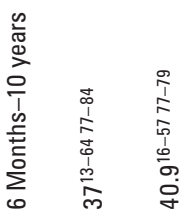

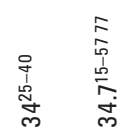

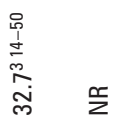

核 这

졸

$\sum_{4}$

딴

疍

in ì g

मे

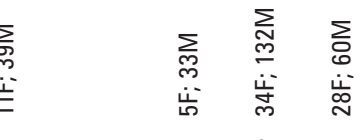

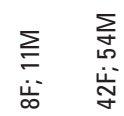

m

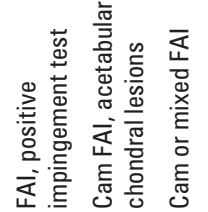

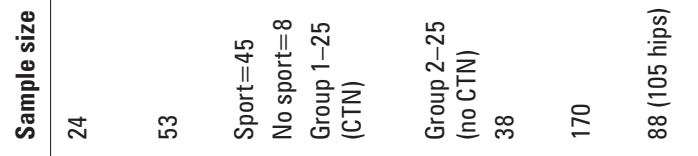

产

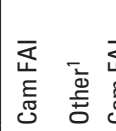

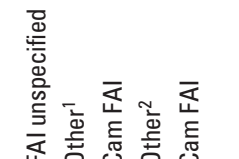

$\div \quad 8$

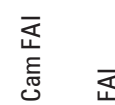

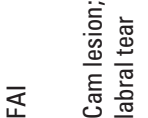
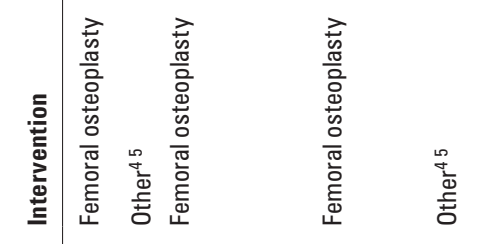

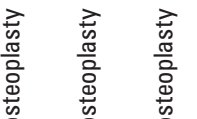

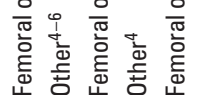

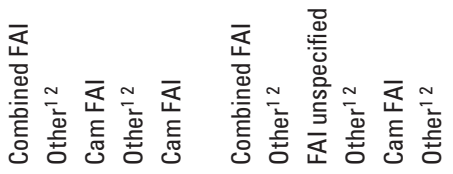

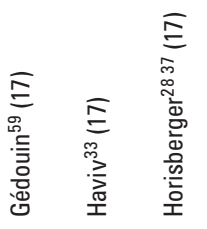

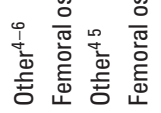
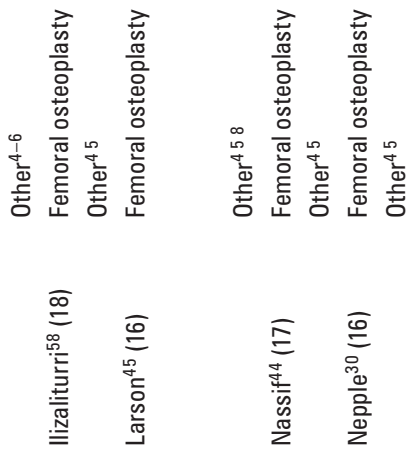

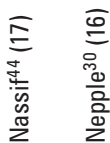




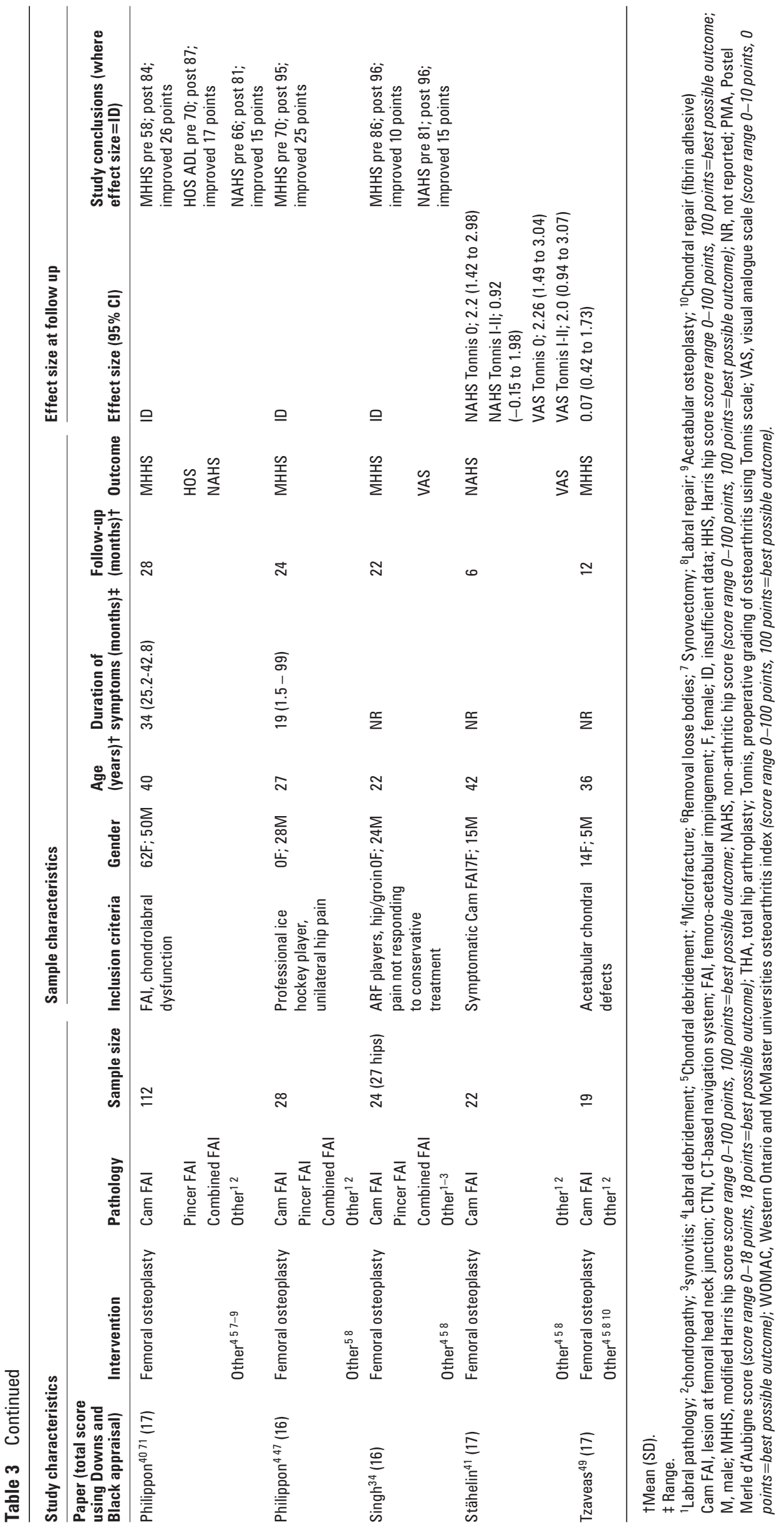

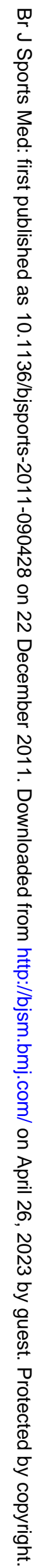


who received the osteoplasty reported excellent or good results compared with arthroscopy alone $(\mathrm{p}=0.043)$, although no difference was observed in the postoperative MHHS between surgical groups $(p=0.11)$. Similarly, Nepple and colleagues ${ }^{30}$ compared two groups who underwent hip arthroscopy with or without femoral osteoplasty for the treatment of cam-type impingement. Unlike Bardakos et al, group allocation within this retrospective study was determined by the time of surgery, as procedures performed at later dates utilised operative techniques that included osteoplasty. The authors reported a significantly higher MHHS in the osteoplasty group 1 year after surgery $(p=0.019)$, and a near-significant trend towards higher MHHS at 2-year follow-up $(p=0.056)$. They also reported a significantly higher likelihood of poor outcome in the non-osteoplasty group $(\mathrm{p}=0.044)$. Brunner et al ${ }^{38}$ prospectively evaluated the addition of a CT-Based Navigation System Prototype to arthroscopic femoral osteoplasty for cam-type impingement. While large effect sizes were found (NAHS and pain VAS) in both groups, there were no between-group differences.

The presence of osteoarthritis at the time of surgery was associated with poorer outcome in two studies. ${ }^{4059}$ Gedouin ${ }^{59}$ demonstrated the effect sizes of 1.17 (WOMAC) and 1.29 (PMA) in participants with FAI without co-existing chondropathy, compared with 0.80 (WOMAC) and 0.87 (PMA) in those with chondropathy. Similarly, Philippon ${ }^{40}$ found that radiographic preoperative hip joint space greater than $2.0 \mathrm{~mm}$ was the predictive of greater MHHS at 28 months follow-up.

\section{DISCUSSION}

Findings of this systematic review indicate that patients with intra-articular hip pathology experience short-term and long-term improvements in pain and physical function following hip arthroscopy, with or without femoral osteoplasty, that appear to be maintained over time. This is despite the heterogeneity seen in study quality, populations and methodologies. Only three studies included patients based on activity level. This could be utilised as an inclusion criterion in future studies to provide further homogeneity to cohorts, therefore providing clinicians with a more accurate reflection on the outcomes for individual patients. Notably, the current review included 12 papers examining hip arthroscopy without osteoplasty and nine papers with osteoplasty that were not included in previous systematic reviews.

Based on findings of 16 studies, current evidence suggests that patients with intra-articular hip pathology will have less pain and increased function for up to 10 years after arthroscopy without femoral osteoplasty. The percentage change in outcome scores ranged from $20 \%{ }^{48}$ to $88 \%, 55$ with a median change of $47 \%$. This magnitude of improvement was also seen 10 years after surgery, with three studies reporting 10 year outcome scores of 88,56 and $45 \%$, respectively. ${ }^{54-56}$ This finding advances on previous systematic reviews, which noted improvements up to 5 years, and may provide confidence for clinicians and patients who are uncertain about the likely longterm benefits of hip arthroscopy surgery. Similarly, evidence from 15 studies demonstrates that patients will also report improvements in pain and function following arthroscopy with femoral osteoplasty. As osteoplasty for FAI is a relatively new procedure, as evidenced by the publication of all included studies in the past 3 years (2008-2010), current follow-up periods only extend to 2.5 years leaving uncertainty regarding the longer-term outcomes of this intervention. Furthermore, the impact of FAI surgery on the development of osteoarthritis of the hip remains unknown.

While the heterogeneity in study methods precludes direct comparisons between hip arthroscopy with and without osteoplasty, inspection of effect sizes (figures 2 and 3 ) indicates similar short-term outcomes between surgical procedures. Only two studies compared the outcomes between osteoplasty and no osteoplasty for patients with FAI. ${ }^{30}{ }^{31}$ Despite inconsistent methodologies, both studies reported better outcomes in those who had undergone osteoplasty, with more osteoplasty patients reporting an excellent outcome $(83 \%$ vs $60 \%, p=0.043)^{31}$ or a change of $40 \%{ }^{30}$ While this needs to be confirmed using rigorous RCT methods, it appears that hip osteoplasty produces short-term results at least as good as those obtained by hip arthroscopy alone.

The radiological feature of cam-type or pincer-type FAI may result in damage to other hip structures, ultimately resulting in pain perception and hip-related symptoms. Hence, hip osteoplasty is increasingly performed to enable greater range of hip joint motion, with the aim of preventing further impingement episodes. Furthermore, since FAI or acetabular dysplasia may lead to early hip osteoarthritis, ${ }^{911}$ hip osteoplasty may play a role in the prevention of structural disease progression. However, until the long-term benefits of osteoplasty are demonstrated with respect to changing the natural course of OA, or rigorous head-to-head comparisons are made with hip arthroscopy alone, any potential additional benefits are theoretical.

Although this systematic review did not specifically examine the effects of hip arthroscopy on individuals with structural hip joint disease (chondropathy through to osteoarthritis), 6 of the 29 papers compared surgical outcomes between those with and without joint disease. ${ }^{4} 4851555659$ In patients with advanced chondropathy or pre-existing osteoarthritis, the outcomes for function and pain were lower when arthroscopy was performed alone ${ }^{485156}$ or with osteoplasty. ${ }^{59}$ These results are similar to those reported at the knee. ${ }^{60}$ Indeed, arthroscopic knee surgery is not recommended as an intervention to address pain and impaired function in patients with knee osteoarthritis ${ }^{61}{ }^{62}$ due to minimal positive effects observed. Therefore, it is important that future studies investigate the impact of joint disease on hip arthroscopy outcomes, and whether arthroscopy can alter the natural progression of symptomatic or structural disease in patients with FAI and/or other intra-articular hip pathology.

The potential for adverse events associated with hip arthroscopy is an important factor in the clinical decision-making process regarding the appropriateness of surgery for an individual. While the reported incidence was low (7\%), it must be considered that only 12 of the 29 studies reported adverse events data. Nevertheless, this complication rate compares favourably with that of knee arthroscopy, where rates of $13-58 \%$ have been reported in populations undergoing arthroscopic anterior cruciate ligament (ACL) reconstructive surgery of the knee. ${ }^{63}$ ${ }^{64}$ The majority ( $83 \%$ ) of the adverse events reported (43 of 52 ) were of transient neuropraxia.

This is the first systematic review to appraise the methodological quality of included studies. Interestingly, the exclusion of studies of poorer quality did not influence the conclusions, when compared with previous systematic reviews. This enhances confidence in the previous and the current findings. Quality appraisal revealed several methodological issues associated with the current hip arthroscopy literature. This 
is apparent in the overall quality rating scores, which ranged from $29 \%$ to $68 \%$ on the Downs and Black scale, and resulted in the exclusion of 11 studies. Foremost, of the 29 studies retained for analysis, only three studies 303139 included a control or a comparison group, while the remaining 26 were case series. Unlike RCTs, case series do not allow for improvements due to placebo or natural recovery to be documented, as noted in a RCT for arthroscopic knee surgery. ${ }^{65}$ To date, there are no RCTs examining outcomes following hip arthroscopy. Although the use of non-controlled study designs makes it difficult to implement the methodological features such as allocation concealment and participant and assessor blinding to decrease the risk of bias, the methodological quality of such studies can be enhanced by utilising prospective designs and blinded examiners.

One major methodological flaw in the included papers was the lack of known psychometric properties of the outcome measures used. It is recognised that PROs used to measure a change in pain and function following an intervention should demonstrate adequate reliability, validity and responsiveness for that population. ${ }^{66}$ However, most of measures used had not been tested for reliability, validity or responsiveness in hip arthroscopy populations. In particular, only one study utilised an outcome measure with demonstrated responsiveness. ${ }^{47}$ This greatly impairs the readers' confidence in the accuracy of results reported in the included papers and in effect sizes calculated. ${ }^{57}$ In addition, only one study attempted to blind observers to outcomes observed. ${ }^{38} 39$ This creates further doubt regarding the efficacy of reported results, as observer-administered outcome measures have been shown to produce higher results than patient-administered measures. ${ }^{67}$

Furthermore, three particular methodological limitations impacted on the ability to compare the effect sizes between studies. First, there was a dearth of data reporting in primary publications, with only 7 of the 29 studies reporting sufficient data for calculation of effect sizes. Second, 12 different outcome measures were utilised. This may be attributed to the relatively recent development of this procedure, and a lack of consensus regarding the most appropriate outcome measures for this diverse population. Third, reported follow-up times varied considerably, ranging from 6 months, ${ }^{41}$ to 10 years. ${ }^{54} 56$ As hip arthroscopy progresses in popularity and further studies evaluate the outcomes of this procedure, it is essential that a battery of valid and reliable outcome measures specific for this population be established. Short- and long-term follow-up data, beyond the current 10 years, are required across multiple postoperative time points.

While the current review examined surgical outcomes, it is plausible that non-surgical approaches also play an integral role in the management of intra-articular hip pathologies. At the knee, a number of RCTs have directly compared the efficacy of surgery with physical therapy or rehabilitation, ${ }^{64} 68$ with all studies noting no superiority of the surgery. In comparison, the clinical commentaries describing rehabilitation of the hip ${ }^{69-72}$ have not examined the outcomes of conservative approaches, in isolation or combined with surgical interventions. The importance of the hip musculature is highlighted by their morphological, biomechanical and physiological characteristics ${ }^{7374}$ and changes seen in the hip muscle size in the presence of hip osteoarthritis. ${ }^{7576}$ Future interdisciplinary studies examining the isolated and combined effects of surgery and rehabilitation may assist in guiding patients to the most appropriate treatment choice.

\section{What is already known on this topic}

- Hip pathology is a common cause of groin pain in active populations.

- Hip arthroscopic surgery is increasing in prevalence.

- Early surgical procedures typically involved labral/chondral debridement. Previous systematic reviews have noted generally good outcomes, with significant reduction in pain and improved function demonstrated for up to 40 months postsurgery.

- Current surgical procedures also target the underlying pathology/abnormal morphology (eg, femoro-acetabular impingement). While short-term outcomes of hip arthroscopic surgery involving osteoplasty appear to be good, medium- or longer-term results remain unclear.

\section{What this study adds}

- Ten-year follow-up data on procedures without osteoplasty demonstrate good results.

- Effect sizes of the benefits observed are similar between surgery involving osteoplasty and no osteoplasty.

- Although some benefit is observed, the presence of chondropathy at the time of surgery results in poorer outcome than cases with normal cartilage.

\section{What remains unknown}

- Whether hip arthroscopy with osteoplasty will improve long-term pain and function.

- Whether hip arthroscopy with osteoplasty will impact on long-term development of hip $0 \mathrm{~A}$.

In summary, current evidence indicates that hip arthroscopy surgery can reduce pain and improve function in patients with intra-articular hip pathology, including FAI, but excluding osteoarthritis as primary pathology. However, these results must be interpreted with caution given the methodological flaws in the included studies. While it has been demonstrated that this improvement can be obtained up to 10 years postsurgery if osteoplasty is not performed, the effects of osteoplasty beyond 3 years have not yet been established. Further high quality comparative studies are required, particularly investigating longer-term effects of osteoplasty and the role of rehabilitation in this patient population, and the outcomes for patients with osteoarthritis.

Acknowledgements JLK is the recipient of a Beryl Haines Memorial Grant from the Physiotherapy Research Foundation (Australia). NC is supported by a National Health and Medical Research Council (Australia), Health Professional Research Training (Post-Doctoral) Fellowship (No. 628918). MM is supported by a National Health and Medical Research Council (Australia) Health Professional Research Training (Post-Doctoral) Fellowship. AGS, ZM and KMC did not receive direct funding from external sources.

Competing interests None.

Provenance and peer review Not commissioned; externally peer reviewed. 


\section{REFERENCES}

1. Ganz R, Parvizi J, Beck M, et al. Femoroacetabular impingement: a cause for osteoarthritis of the hip. Clin Orthop Relat Res 2003:417:112-20.

2. Parvizi J, Bican 0, Bender B, et al. Arthroscopy for labral tears in patients with developmental dysplasia of the hip: a cautionary note. J Arthroplasty 2009;24:110-13

3. Burnett RS, Della Rocca GJ, Prather H, et al. Clinical presentation of patients with tears of the acetabular labrum. J Bone Joint Surg Am 2006;88:1448-57.

4. Philippon MJ, Weiss DR, Kuppersmith DA, et al. Arthroscopic labral repair and treatment of femoroacetabular impingement in professional hockey players. Am J Sports Med 2010;38:99-104.

5. Bradshaw CJ, Bundy M, Falvey E. The diagnosis of longstanding groin pain: a prospective clinical cohort study. Br J Sports Med 2008;42:851-4.

6. Byrd JW, Jones KS. Hip arthroscopy in athletes. Clin Sports Med 2001;20:749-61

7. MillenniumResearchGroup. Hip Arthroscopy Procedures to Soar, 2009. http:// www.bio-medicine.org/medicine-news-1/Hip-Arthroscopy-Procedures-to-SoarThrough-2013-51045-1/26.10.2009. (accessed 31 Aug 2011)

8. Nepple JJ, Carlisle JC, Nunley RM, et al. Clinical and radiographic predictors of intra-articular hip disease in arthroscopy. Am J Sports Med 2011;39:296-303.

9. Lievense AM, Bierma-Zeinstra SM, Verhagen AP, et al. Influence of hip dysplasia on the development of osteoarthritis of the hip. Ann Rheum Dis 2004;63:621-6.

10. Reijman M, Hazes JM, Pols HA, et al. Role of radiography in predicting progression of osteoarthritis of the hip: prospective cohort study. BMJ 2005;330:1183.

11. Lane NE, Lin P, Christiansen L, et al. Association of mild acetabular dysplasia with an increased risk of incident hip osteoarthritis in elderly white women: the study of osteoporotic fractures. Arthritis Rheum 2000;43:400-4.

12. Ng VY, Arora N, Best TM, et al. Efficacy of surgery for femoroacetabular impingement: a systematic review. Am J Sports Med 2010;38:2337-45.

13. Bedi A, Chen N, Robertson W, et al. The management of labral tears and femoroacetabular impingement of the hip in the young, active patient. Arthroscopy 2008;24:1135-45

14. Baldwin KD, Harrison RA, Namdari S, et al. Outcomes of hip arthroscopy for treatment of femoroacetabular impingement: a systematic review. Curr Orthop Pract 2009;20:669-73.

15. Robertson WJ, Kadrmas WR, Kelly BT. Arthroscopic management of labral tears in the hip: a systematic review of the literature. Clin Orthop Relat Res 2007:455:88-92.

16. Clohisy JC, St John LC, Schutz AL. Surgical treatment of femoroacetabular impingement: a systematic review of the literature. Clin Orthop Relat Res 2010;468:555-64.

17. Liberati A, Altman DG, Tetzlaff J, et al. The PRISMA statement for reporting systematic reviews and meta-analyses of studies that evaluate health care interventions: explanation and elaboration. PLoS Med 2009;6:e1000100

18. Sackett DL, Wennberg JE. Choosing the best research design for each question. BMJ 1997;315:1636

19. Coleman KN, Norris S, Weston A, et al. NHMRC additional levels of evidence and grades for recommendations for developers of guidelines. National Health and Medical Research Council (NHMRC) Australia, 2009 (cited 2011 08.02.2011). http://www.nhmrc.gov.au/_files_nhmrc/file/ guidelines/Stage\%202\%20Consultation\%20Levels\%20and\%20Grades.pdf (accessed 8 Feb 2011).

20. Downs SH, Black N. The feasibility of creating a checklist for the assessment of the methodological quality both of randomised and non-randomised studies of health care interventions. J Epidemiol Community Health 1998;52:377-84

21. Deeks JJ, Dinnes J, D'Amico R, et al. Evaluating non-randomised intervention studies. Health Technol Assess 2003; 7:iii-x, 1-173.

22. Saunders LD, Soomro GM, Buckingham J, et al. Assessing the methodological quality of nonrandomized intervention studies. West J Nurs Res 2003;25:223-37.

23. Hopkins W. A new view of statistics. Summarizing data: Precision of measurement, 2000 (cited 2011). http://www.sportsci.org/resource/stats/index html (accessed 3 Mar 2011).

24. Portney L, Watkins M. Foundations of Clinical Research - Applications to Clinical Practice. Third edition. New Jersey, Upper Saddle River: Pearson Education 2009.

25. Collins N, Bisset L, McPoil T, et al. Foot orthoses in lower limb overuse conditions: a systematic review and meta-analysis. Foot Ankle Int 2007;28:396-412

26. Cohen Je Statistical power analysis for the behavioral sciences. Second edition. Hillsdale, N J: Lawrence Erlbaum Associates 1988.

27. Confidence Interval for the Difference of Means Assuming Equal Variance Applet. Texas A\&M University (cited 2011 25.01.2011). http://www.stat.tamu. edu/ jhardin/applets/signed/case8.html (accessed 25 Sep 2011).

28. Horisberger M, Brunner A, Herzog RF. Arthroscopic treatment of femoral acetabular impingement in patients with preoperative generalized degenerative changes. Arthroscopy 2010;26:623-9

29. Margheritini F, Villar RN. The efficacy of arthroscopy in the treatment of hip osteoarthritis. Chir Organi Mov 1999;84:257-61.
30. Nepple JJ, Zebala LP, Clohisy JC. Labral disease associated with femoroacetabular impingement: do we need to correct the structural deformity? J Arthroplasty 2009;24:114-19.

31. Bardakos NV, Vasconcelos JC, Villar RN. Early outcome of hip arthroscopy for femoroacetabular impingement: the role of femoral osteoplasty in symptomatic improvement. J Bone Joint Surg Br 2008;90:1570-5.

32. Yamamoto $\mathbf{Y}$, Ide T, Nakamura M, et al. Arthroscopic partial limbectomy in hip joints with acetabular hypoplasia. Arthroscopy 2005;21:586-91.

33. Haviv B, Singh PJ, Takla A, et al. Arthroscopic femoral osteochondroplasty for cam lesions with isolated acetabular chondral damage. J Bone Joint Surg Br 2010;92:629-33

34. Singh PJ, O'Donnell JM. The outcome of hip arthroscopy in Australian football league players: a review of 27 hips. Arthroscopy 2010;26:743-9.

35. Prather $\mathbf{H}$, Hunt D, Fournie A, et al. Early intra-articular hip disease presenting with posterior pelvic and groin pain. PM R 2009;1:809-15.

36. Kocher MS SR, Lee BM, Micheli LJ, et al. Arthroscopic debridement of hip labra tears in dancers. Journal of Dance Medicine \& Science 2006;10:99-105.

37. Horisberger M, Brunner A, Herzog RF. Arthroscopic treatment of femoroacetabular impingement of the hip: a new technique to access the joint. Clin Orthop Relat Res 2010;468:182-90.

38. Brunner A, Horisberger M, Herzog RF. Evaluation of a computed tomographybased navigation system prototype for hip arthroscopy in the treatment of femoroacetabular cam impingement. Arthroscopy 2009;25:382-91.

39. Brunner A, Horisberger M, Herzog RF. Sports and recreation activity of patients with femoroacetabular impingement before and after arthroscopic osteoplasty. Am J Sports Med 2009;37:917-22

40. Philippon MJ, Briggs KK, Yen YM, et al. Outcomes following hip arthroscopy for femoroacetabular impingement with associated chondrolabral dysfunction: minimum two-year follow-up. J Bone Joint Surg Br 2009;91:16-23.

41. Stähelin L, Stähelin T, Jolles BM, et al. Arthroscopic offset restoration in femoroacetabular cam impingement: accuracy and early clinical outcome. Arthroscopy 2008;24:51-57 e1.

42. Thorborg K, Roos EM, Bartels EM, et al. Validity, reliability and responsiveness of patient-reported outcome questionnaires when assessing hip and groin disability: a systematic review. Br J Sports Med 2010;44:1186-96.

43. Söderman $\mathbf{P}$, Malchau $H$, Herberts P. Outcome of total hip replacement: a comparison of different measurement methods. Clin Orthop Relat Res 2001;390:163-72

44. Nassif NA, Pekmezci M, Pashos G, et al. Osseous remodeling after femoral head-neck junction osteochondroplasty. Clin Orthop Relat Res 2010;468:511-18.

45. Larson CM, Giveans MR. Arthroscopic management of femoroacetabular impingement: early outcomes measures. Arthroscopy 2008;24:540-6.

46. Freedman BA, Potter BK, Dinauer PA, et al. Prognostic value of magnetic resonance arthrography for Czerny stage II and III acetabular labral tears. Arthroscopy 2006;22:742-7.

47. Philippon MJ, Wolff AB, Briggs KK, et al. Acetabular rim reduction for the treatment of femoroacetabular impingement correlates with preoperative and postoperative center-edge angle. Arthroscopy 2010;26:757-61.

48. Streich NA, Gotterbarm T, Barié A, et al. Prognostic value of chondral defects on the outcome after arthroscopic treatment of acetabular labral tears. Knee Surg Sports Traumatol Arthrosc 2009;17:1257-63.

49. Tzaveas AP, Villar RN. Arthroscopic repair of acetabular chondral delamination with fibrin adhesive. Hip Int 2010;20:115-19.

50. Kamath AF, Componovo R, Baldwin K, et al. Hip arthroscopy for labral tears: review of clinical outcomes with 4.8-year mean follow-up. Am J Sports Med 2009;37:1721-7

51. Byrd JW, Jones KS. Prospective analysis of hip arthroscopy with 2-year follow-up. Arthroscopy 2000;16:578-87.

52. Byrd JW, Jones KS. Hip arthroscopy in the presence of dysplasia. Arthroscopy 2003;19:1055-60.

53. Byrd JW, Jones KS. Traumatic rupture of the ligamentum teres as a source of hip pain. Arthroscopy 2004;20:385-91.

54. Byrd JW, Jones KS. Hip arthroscopy in athletes: 10-year follow-up. Am J Sports Med 2009;37:2140-3.

55. Byrd JW, Jones KS. Hip arthroscopy for labral pathology: prospective analysis with 10-year follow-up. Arthroscopy 2009;25:365-8.

56. Byrd JW, Jones KS. Prospective analysis of hip arthroscopy with 10-year followup. Clin Orthop Relat Res 2010:468:741-6.

57. Fitzpatrick R, Davey C, Buxton MJ, et al. Evaluating patient-based outcome measures for use in clinical trials. Health Technol Assess 1998;2:i-iv, 1-74.

58. Ilizaliturri VM Jr, Orozco-Rodriguez L, Acosta-Rodríguez E, et al. Arthroscopic treatment of cam-type femoroacetabular impingement: preliminary report at 2 years minimum follow-up. J Arthroplasty 2008;23:226-34.

59. Gédouin JE, Duperron D, Langlais F, et al. Update to femoroacetabula impingement arthroscopic management. Orthop Traumatol Surg Res 2010;96:222-7. 
60. Samson DJ, Grant MD, Ratko TA, et al. Treatment of primary and secondary osteoarthritis of the knee. Evid Rep Technol Assess 2007;157:1-157.

61. Zhang W, Moskowitz RW, Nuki G, et al. OARSI recommendations for the management of hip and knee osteoarthritis, part I: critical appraisal of existing treatment guidelines and systematic review of current research evidence. Osteoarthr Cartil 2007;15:981-1000.

62. Zhang W, Moskowitz RW, Nuki G, et al. OARSI recommendations for the management of hip and knee osteoarthritis, Part II: OARSI evidence-based, expert consensus guidelines. Osteoarthr Cartil 2008;16:137-62.

63. Jameson SS, Dowen D, James P, et al. Complications following anterior cruciate ligament reconstruction in the English NHS. Knee 2012;19:14-19.

64. Frobell RB, Roos EM, Roos HP, et al. A randomized trial of treatment for acute anterior cruciate ligament tears. N Engl J Med 2010;363:331-42.

65. Moseley JB, O'Malley K, Petersen NJ, et al. A controlled trial of arthroscopic surgery for osteoarthritis of the knee. N Engl J Med 2002;347:81-8.

66. Dawson J, Doll H, Fitzpatrick R, et al. The routine use of patient reported outcome measures in healthcare settings. BMJ 2010;340:c186.

67. Palfreyman S. Patient-reported outcome measures and how they are used. Nurs Older People 2011;23:31-6.

68. Linko E, Harilainen A, Malmivaara A, et al. Surgical versus conservative interventions for anterior cruciate ligament ruptures in adults. Cochrane Database Syst Rev 2005;2:CD001356.

69. Stalzer S, Wahoff M, Scanlan M. Rehabilitation following hip arthroscopy. Clin Sports Med 2006;25:337-57, x.

70. Enseki KR, Martin RL, Draovitch P, et al. The hip joint: arthroscopic procedures and postoperative rehabilitation. J Orthop Sports Phys Ther 2006;36:516-25.

71. Philippon MJ, Christensen JC, Wahoff MS. Rehabilitation after arthroscopic repair of intra-articular disorders of the hip in a professional football athlete. J Sport Rehabil 2009;18:118-34.

72. Enseki KR, Martin R, Kelly BT. Rehabilitation after arthroscopic decompression for femoroacetabular impingement. Clin Sports Med 2010;29:247-55, viii.

73. Ward SR, Winters TM, Blemker SS. The architectural design of the glutea muscle group: implications for movement and rehabilitation. J Orthop Sports Phys Ther 2010;40:95-102.
74. Neumann DA. Kinesiology of the hip: a focus on muscular actions. J Orthop Sports Phys Ther 2010;40:82-94.

75. Grimaldi A, Richardson C, Durbridge G, et al. The association between degenerative hip joint pathology and size of the gluteus maximus and tensor fascia lata muscles. Man Ther 2009;14:611-17.

76. Grimaldi A, Richardson C, Stanton W, et al. The association between degenerative hip joint pathology and size of the gluteus medius, gluteus minimus and piriformis muscles. Man Ther 2009;14:605-10.

77. Boonstra AM, Schiphorst Preuper HR, Reneman MF, et al. Reliability and validity of the visual analogue scale for disability in patients with chronic musculoskeletal pain. Int J Rehabil Res 2008;31:165-9

78. Olaogun MOB, Adedoyin RA, Ikem IC, et al. Reliability of rating low back pain with a visual analogue scale and a semantic differential scale. Physioth Theory Pract 2004;20:135-42.

79. Tijssen M, van Cingel $\mathrm{R}$, van Melick N, et al. Patient-Reported Outcome questionnaires for hip arthroscopy: a systematic review of the psychometric evidence. BMC Musculoskelet Disord 2011;12:117.

80. Basaran S, Guzel R, Seydaoglu G, et al. Validity, reliability, and comparison of the WOMAC osteoarthritis index and Lequesne algofunctional index in Turkish patients with hip or knee osteoarthritis. Clin Rheumatol 2010;29:749-56.

81. Faucher M, Poiraudeau S, Lefevre-Colau MM, et al. Assessment of the testretest reliability and construct validity of a modified WOMAC index in knee osteoarthritis. Joint Bone Spine 2004;71:121-7.

82. Delaunay C, Epinette JA, Dawson J, et al. Cross-cultural adaptations of the Oxford-12 HIP score to the French speaking population. Orthop Traumatol Surg Res 2009;95:89-99.

83. Okonkwo OC, Roth DL, Pulley L, et al. Confirmatory factor analysis of the validity of the SF-12 for persons with and without a history of stroke. Qual Life Res 2010;19:1323-31.

84. Valderrabano V, Pagenstert G, Horisberger M, et al. Sports and recreation activity of ankle arthritis patients before and after total ankle replacement. Am J Sports Med 2006;34:993-9. 